\title{
Hydrophobic micro/mesoporous silica spheres assembled from zeolite precursors in acidic media for aromatics adsorption
}

\author{
Baojuan Dou ${ }^{\mathrm{a}}$, Jinjun $\mathrm{Li}^{\mathrm{a}}$, Qin $\mathrm{Hu}^{\mathrm{a}}$, Chunyan Ma ${ }^{\mathrm{a}}$, Chi He ${ }^{\mathrm{a}}$, Peng $\mathrm{Li}^{\mathrm{a}}$, Qiuhong $\mathrm{Hu}^{\mathrm{b}}$, Zhengping Hao ${ }^{\mathrm{a}, *}$, \\ Shizhang Qiao ${ }^{\mathrm{b}, * *}$ \\ a Department of Environmental Nano-materials, Research Center for Eco-Environmental Sciences, Chinese Academy of Sciences, Beijing 100085, PR China \\ ${ }^{\mathrm{b}}$ ARC Centre for Functional Nanomaterials, Australian Institute for Bioengineering and Nanotechnology, The University of Queensland, Brisbane, QLD 4072, Australia
}

\section{A R T I C L E I N F O}

Article history:

Received 6 January 2010

Received in revised form 21 April 2010

Accepted 26 April 2010

Available online 29 April 2010

\section{Keywords:}

Acidic media

Micro/mesoporous materials

Microporosity

VOCs adsorption

Hydrophobicity

\begin{abstract}
A B S T R A C T
The micro/mesoscopic silicas (MMS) were successfully synthesized with a self-assembly approach by employing silicalite-1 zeolite seeds as precursors in acid media. The resulting MMS samples were characterized by X-ray diffraction (XRD), nitrogen adsorption/desorption, n-nonane pre-adsorption and transmission electron microscopy (TEM). After aging for $18 \mathrm{~h}$, the obtained materials exhibit both well-defined low- and high-angle XRD peaks. The XRD results combined with other characterizations confirm that the zeolite precursors, after aging for $18 \mathrm{~h}$, were assembled to hierarchical porous composites, featuring both zeolite-like microporous and mesoporous structures rather than a physical mixture of bulk zeolite and mesoporous solid. It was found that the MMS samples exhibit spherical morphology, with high surface area and large total pore volume. Even with the aging time increasing up to $24 \mathrm{~h}$, the obtained biporous composite MMS-24 still presents high surface area of $536 \mathrm{~m}^{2} \mathrm{~g}^{-1}$ and large total pore volume of $0.66 \mathrm{~cm}^{3} \mathrm{~g}^{-1}$. The adsorption of benzene by the hierarchical materials under static and dynamic conditions was also investigated. The results of the adsorption isotherms and isosteric adsorption heat reveal that MMS-24 represents super hydrophobicity and high affinity towards aromatics. The adsorption capacity of benzene on MMS-24 is approximately three times higher than that on silicalite- 1 zeolite. As indicated by the adsorption dynamic study, MMS-24 has high tendency towards benzene in the presence of water vapor, retaining high benzene removal efficiency (85\%) comparing with that under dry condition.
\end{abstract}

(c) 2010 Elsevier Inc. All rights reserved.

\section{Introduction}

In compliance with the latest environmental standards, adsorption technology for the removal of volatile organic compounds (VOCs) has been recognized as a preferred strategy because it provides additional benefits from the recovery of the valuable adsorbates $[1,2]$. An ideal adsorbent adopted in the industrial process should possess excellent adsorptive capacity, high adsorption and desorption rate for adsorbate, long life and stability under operating conditions [3]. Activated carbon as a typical adsorbent, unfortunately, suffers from fire risk, pore clogging, hygroscopicity and a lack of regenerative ability [4] when it is used for the removal of VOCs under various operational conditions.

Zeolite and mesoporous materials have been intensively investigated as alternative adsorbents because they possess unique advantages of high adsorption capacity, reliable desorption perfor-

\footnotetext{
* Corresponding author. Tel.: +86 10 62849194; fax: +86 1062923564 .

** Corresponding author.

E-mail addresses: zpinghao@rcees.ac.cn (Z. Hao), s.qiao@uq.edu.au (S. Qiao).
}

mance and excellent hydrothermal and chemical stability [2,5]. Silicalite-1 zeolite is a high hydrophobic material due to its perfect three dimensional $\mathrm{Si}-\mathrm{O}-\mathrm{Si}$ binding structure with no cations and silanol defects on the surface [6]. However, serious diffusion restrictions imposed by micropores $(<2 \mathrm{~nm})$ in zeolite tend to inhibit its ability to adsorb large VOCs molecules [7]. Although mesoporous silicas have larger pores and high surface area which make them accessible to bulky molecules, their hydrophilic feature due to a large number of silanols $(\mathrm{Si}-\mathrm{OH})$ on their amorphous wall surfaces still affects their ability for the removal of VOCs. It is reported that the amount of VOCs adsorbed on silica-based mesoporous materials could be significantly influenced by the presence of water vapor because of the strong interaction between water molecules and silanols $[8,9]$. Hence it is expected that the composite materials derived from the combination of microporous zeolite and mesoporous materials will significantly improve the hydrophobicity and the adsorption capacity of the materials.

To date, many investigations have been undertaken to develop pathways for the synthesis of micro/mesoporous materials, such as dealumination/desilication [10-12], recrystallisation [13-15], 
carbon based methods [16,17], deposition [18,19] and templating approach [20-25]. With respect to the templating approach, using zeolite seeds containing subunits of the zeolite as precursors was proved to be effective for the assembly of mesostructured silicas. This technique was first demonstrated by utilizing faujasitic zeolite seeds (FAU) to construct the walls of MCM-41 under basic conditions compatible with protozeolitic seeds formation [21], and subsequently it was extensively furthered [26-28]. In comparison with MCM-41, SBA-15 has much thicker walls $(>3 \mathrm{~nm}$ ), larger pores (5-30 nm) and higher stability. Liu and Pinnavaia [20] incorporated zeolite nanoclusters into SBA-15 structures under acidic condition. As a result, a porous material containing both micropores and mesopores was synthesized from preformed silicalite-1 colloidal precursors at room temperature, under which self-assembly process is easy to utilize [22]. Han et al. [29] successfully prepared ordered mesoporous aluminosilicates/silica by assembly of preformed aluminosilicate/silica precursors on a triblock polymer template under strong acidic conditions. Although the aforementioned bimodal materials exhibited well-defined small-angle Xray diffraction (XRD) patterns indicating an ordered mesoporous structure, they did not show wide-angle XRD patterns assigned to conventional zeolites framework. This fact indicates that it is difficult to incorporate heteroelements into silica framework during the synthesis under low $\mathrm{pH}$ conditions. Actually, the biporous materials do not possess long-range atomic order characterized as crystalline zeolite frameworks hence inhibiting their industrial applications. Moreover, there is limited information available in literature relating to the investigation on the hydrophobicity and adsorption properties of the biporous silicas synthesized in acidic media and their application in the field of VOCs removal [30,31].

Herein, we successfully prepared a series of hierarchical micro/ mesoscopic silicas (MMS) which exhibit both zeolite-like microporous and mesoporous structures. The spherical silicas were synthesized under acidic condition using silicalite- 1 zeolite seeds as precursors and Pluronic P123 (EO20PO70EO20) as a surfactant, coupled with desired cetyltrimethylammonium bromide (CTAB) as a co-surfactant. The microporosity in the MMS was evaluated by selective blocking of micropores using n-nonane as a probe molecule. MMS hydrophobicity, as well as static and dynamic adsorption properties for the removal of VOCs were intensively studied by a digital microbalance and the flow adsorption measurements. The results indicate that the obtained biporous silicas, containing both zeolite-like microporous and mesoporous structures, have super hydrophobicity and high adsorption capacity for aromatics, which are believed to be potential adsorbents for VOCs removal.

\section{Experimental section}

\subsection{Material synthesis}

The synthetic procedures of MMS are described as follow. The preformed precursor solution with silicalite-1 primary and secondary building units (silicalite- 1 nanoclusters solution) was prepared according to the literature [32]. Of $4.5 \mathrm{~g}$ tetraethyl orthosilicate (TEOS, Aldrich) was added to $7.9 \mathrm{~g}$ of tetrapropylammonium hydroxide solution (TPAOH, 20\%) under stirring condition at room temperature for $30 \mathrm{~min}$. The homogenous solution with the molar composition of 1 TEOS:0.36 TPAOH: $18 \mathrm{H}_{2} \mathrm{O}$ was aged at $95{ }^{\circ} \mathrm{C}$ for various periods of time $(0-24 \mathrm{~h})$ and then cooled to room temperature. The obtained precursors of silicalite- 1 with different aging time were then ready to react with a surfactant solution in order to assemble the mesoporous structure.

The mesoporous material was synthesized referring to the procedure reported previously [33]. Of $3 \mathrm{~g}$ Pluronic P123 (Mav $=5800$, Aldrich) and $0.5 \mathrm{~g}$ of cetyltrimethyammonium bromide (CTAB) were dissolved in a solution prepared by mixing of $9.1 \mathrm{~g}$ of $\mathrm{HCl}$ (37\%), $79.2 \mathrm{~g}$ of deionized (DI) water and $20 \mathrm{~mL}$ of ethanol to make a surfactant solution. Then the preformed silicalite-1 solution was added to the surfactant solution drop by drop under vigorous stirring and reacted at $35^{\circ} \mathrm{C}$ for $45 \mathrm{~min}$. Then the mixture was transferred to a PTFE autoclave, heated under static condition at $75^{\circ} \mathrm{C}$ for $10 \mathrm{~h}$, and further kept at higher temperature of $100^{\circ} \mathrm{C}$ for 2 days. The resulting solid was filtered and washed with DI water repeatedly until the surfactant was completely removed. The solid was dried at $80^{\circ} \mathrm{C}$ for $24 \mathrm{~h}$ before it was calcined in air at $600{ }^{\circ} \mathrm{C}$ for $4 \mathrm{~h}$ to remove the organic template. The samples were denoted as MMS- $x$, where $x$ refers to the hours of silicalite- 1 solution aged.

\subsection{Characterizations and measurements}

The low- and high-angle XRD patterns of the obtained MMS samples were recorded on an Siemens D5005 diffractometer with $\mathrm{Cu} \mathrm{Ka}$ radiation $(\lambda=0.1541 \mathrm{~nm})$ in the $2 \theta$ range from $0.5^{\circ}$ to $6^{\circ}$ and from $5^{\circ}$ to $40^{\circ}$ respectively. Transmission electron microscopy (TEM) images were collected on a Hitachi H-7500 operating at an accelerating voltage of $120 \mathrm{kV}$. High-resolution transmission electron microscopy (HRTEM) analysis was conduced on a JEOL 2011 microscope at $200 \mathrm{kV}$.

Nitrogen adsorption/desorption analysis for MMS was conducted at liquid nitrogen temperature $(77 \mathrm{~K}$ ) using NOVA 1200 gas sorption analyzer. Each sample was degassed under vacuum condition at $200{ }^{\circ} \mathrm{C}$ for $3 \mathrm{~h}$ prior to the measurement. The BET specific surface area was calculated using adsorption data at relative pressure $\left(P / P_{0}\right)$ of $0.05-0.25$, and the total pore volume was estimated from the amount adsorbed at a relative pressure of about 0.99 . The pore size distribution (PSD) was calculated from the analysis of the adsorption branch of the isotherm using the BarrettJoyner-Halenda (BJH) algorithm.

Pre-adsorption of $n$-nonane was conducted following the procedure described in literature [34]. After degassing at $523 \mathrm{~K}$ for $4 \mathrm{~h}$, samples were exposed to $\mathrm{n}$-nonane at $77 \mathrm{~K}$ for $30 \mathrm{~min}$ and then left in liquid n-nonane for $3 \mathrm{~h}$ at room temperature. Then these samples were degassed at $298 \mathrm{~K}$ overnight to completely remove nnonane from the external surface and mesopores of MMS. Following n-nonane desorption, the physical properties of MMS materials were analyzed again using the nitrogen adsorption at $77 \mathrm{~K}$.

\subsection{Dynamic adsorption measurements}

The dynamic adsorption was carried out by a flow method reported by Hu et al. [30]. After degassing at $110^{\circ} \mathrm{C}$ for $24 \mathrm{~h}$, about $1 \mathrm{~g}$ of adsorbent (40-60 mesh) was packed into a glass column. The investigation on benzene adsorption was performed under both dry and wet conditions. The concentration of benzene was controlled at $700 \mathrm{ppm}$ and the total flow rate was $100 \mathrm{~mL} / \mathrm{min}$. To observe the effects of water vapor on the adsorption behaviors of MMS materials, the test gas consisted of nitrogen, $700 \mathrm{ppm}$ of benzene under the relative humidity $(\mathrm{RH})$ of $38 \%$, was passed through the adsorption bed. The amount of benzene adsorbed was calculated by its concentration change before and after the adsorption process, tested by using a gas chromatograph (GC) equipped with a flame ionization detector.

\subsection{Static adsorption measurements}

The static adsorption equilibrium measurements of water and benzene on the MMS materials were recorded by using an Intelligent Gravimetric Analyzer (model IGA-002, Hiden Isochema Instrument) with a sensitivity of $0.1 \mu \mathrm{g}$. The apparatus is an ultrahigh vacuum system allowing isotherms and the corresponding 
kinetics to be determined by setting pressure steps. Before measurements, the samples were degassed at $110^{\circ} \mathrm{C}$ over night.

\section{Results and discussion}

\subsection{Structure of MMS}

Fig. 1 depicts the X-ray diffraction patterns for the MMS samples assembled from silicalite- 1 zeolite seeds with different aging times. All the samples exhibit well-defined low-angle diffraction peaks indexed as $\left(\begin{array}{lll}1 & 0 & 0\end{array}\right)$, representing a mesoporous structure (Fig. 1a). After aging for $18 \mathrm{~h}$, the obtained composites (MMS-18 and MMS-24) still preserve a well-defined mesoporous structure. In the high-angle region, as shown in Fig. 1b, no obvious silicalite- 1 zeolite peaks were observed for MMS-0, MMS-6 and MMS12. Prolonging the aging time to $18 \mathrm{~h}$ or $24 \mathrm{~h}$, a series of distinctive peaks of crystalline silicalite- 1 at $7.8^{\circ}, 8.8^{\circ}, 23^{\circ}, 23.6^{\circ}$ and $24.4^{\circ}$, respectively, were detected for MMS-18 and MMS-24. It is clear that these peaks became sharper and more prominent with the increase of aging time. The obvious appearance of high-angle XRD peaks, especially for the samples aging for more than $18 \mathrm{~h}$, indicates that well crystallized zeolites were successfully embedded in the framework of MMS-18 and MMS-24. In these materials, the mesostructure could be formed though a cooperative supramolecular assembly mechanism that incorporates the interactions between silicalite-1 precursors and surfactant head groups of organic micelles [35]. Compared with other micro-mesoporous materials synthesized in acidic media [20-22], the present MMS-18 and MMS-24 exhibit well-defined XRD peaks in both low- and high-angle region. The XRD results presented in this study show that MMS-18 and MMS-24 are a type of hierarchically structured composite containing both zeolite-like micropores and mesopores.

The nitrogen adsorption and desorption isotherms of MMS materials at $77 \mathrm{~K}$ and the corresponding pore size distributions obtained by the BJH method are shown in Fig. 2. As shown in Fig. 2a, the shape of the adsorption isotherm curves for all the MMS samples can be considered as a combination of type I and type IV according to the IUPAC classification [36]. The shape of the adsorption curves exhibits a steep increase of the adsorbed amount at low relative pressure $\left(P / P_{0}<0.1\right)$ for all the MMS samples, indicating the presence of micropores for these materials. The relative pressure responsible for the capillary condensation associated with mesopores appears at about $P / P_{0}=0.4$. Moreover, with increasing the aging time in the materials preparation, the capillary condensation steps of materials shift towards higher relative pressure, indicating the increase in pore size. For the sample MMS-0, an H2-type hysteresis loop is observed in the region of relative pressure of $0.38-0.68$. This type of hysteresis loop suggests the formation of tubular mesopores containing a narrow constriction or closed pores of the ink-bottle type which are frequently found in worm-like mesopores [37]. It should be noted that, MMS-18 and MMS-24 exhibit well-defined hysteresis loops, confirming that the mesostructure of such bimodal materials was preserved well even after a long aging time. These results are in accordance with the XRD results. For MMS-24, a small uptake at high relative pressure $\left(P / P_{0}>0.9\right)$ is ascribed to the adsorption in the textural pores, which is attributed to the interparticle voids. With the increase of aging time, broader pore size distributions are obtained for the hierarchical porous composites, implying a less ordered mesostructure caused by the increasing domains of zeolite (Fig. 2b).

The Gregg's n-nonane pre-adsorption method [38], proved to be an effective approach to obtain more reliable values in micropore volume, was employed to estimate the microporosity for the MMS samples. The application of this method is under the assumptions that the n-nonane selectively blocks micropores and the
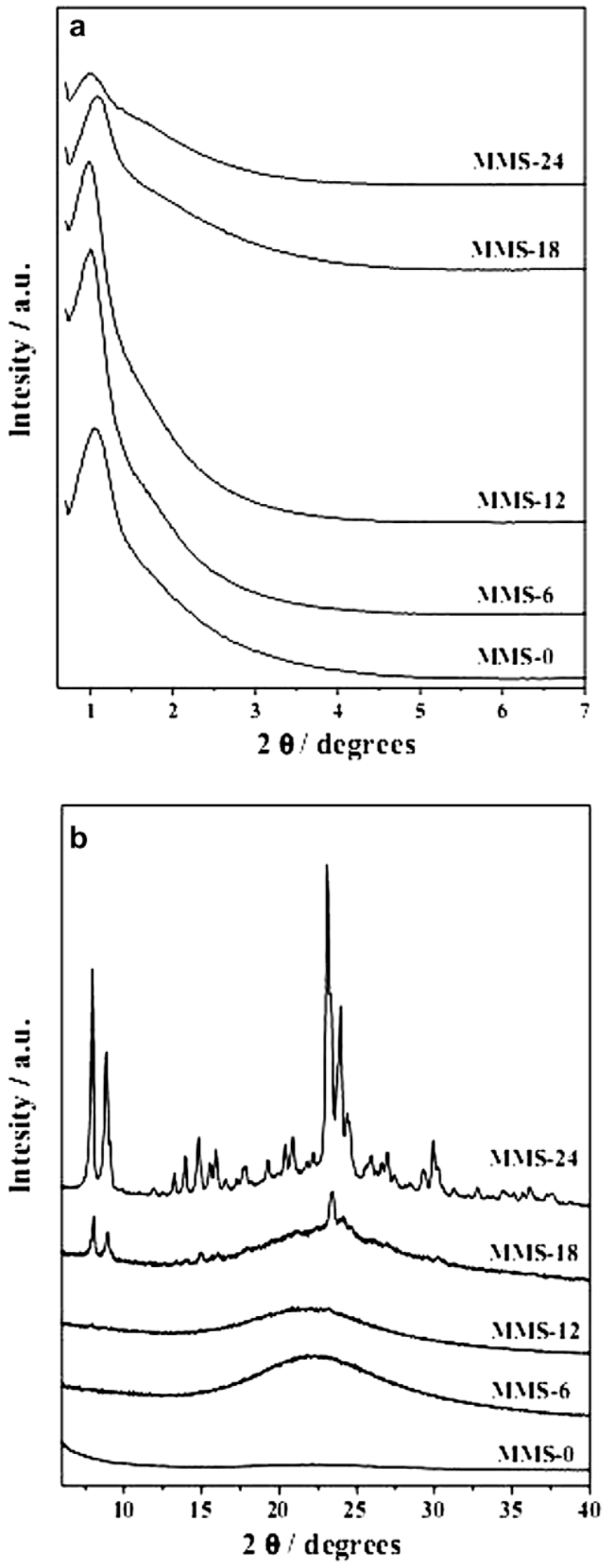

Fig. 1. Low angle X-ray diffraction (a) and wide-angle X-ray diffraction (b) patterns of calcined MMS materials assembled from silicalite- 1 zeolite seeds with different aging times.

trapped n-nonane can not be removed through degassing at room temperature. Hence the micropore volume of porous solids can be obtained by the difference of the adsorbed amount before and after pre-adsorption of n-nonane. Using the LiChrospher Si-1000 silica 

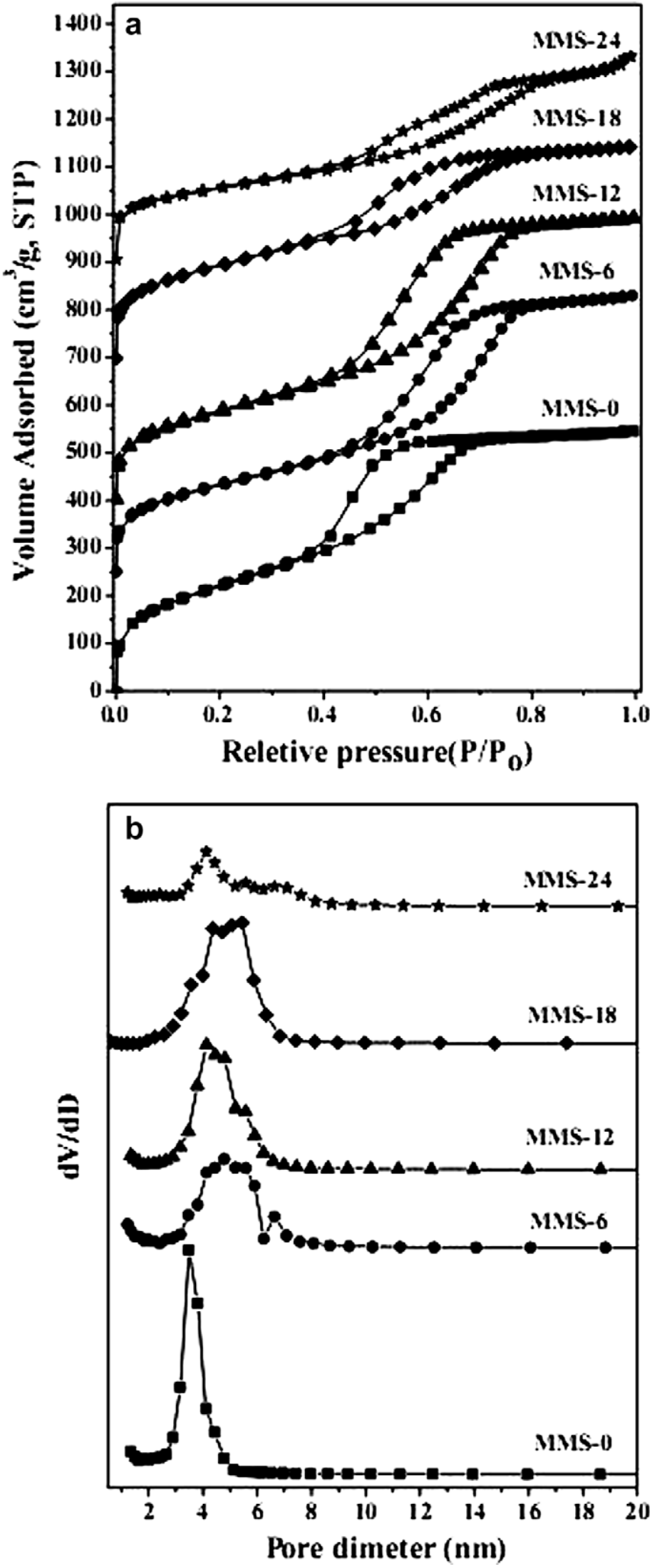

Fig. 2. Nitrogen adsorption/desorption isotherms (a) and BJH pore size distribution (b) of MMS materials assembled from silicalite-1 zeolite seeds with different aging times. The isotherms for MMS-6, MMS-12, MMS-18 and MMS-24 are shifted by 250, 400,700 and $900 \mathrm{~cm}^{3} \mathrm{~g}^{-1} \mathrm{STP}$, respectively.

[39] as a reference sample, the comparative $\alpha_{\mathrm{s}}$ plots corresponding to MMS-0 and MMS-24 materials before and after n-nonane preadsorption are displayed in Fig. 3. With the pre-adsorption of nnonane, the straight lines go through the origin at low $\alpha_{\mathrm{s}}$ values,
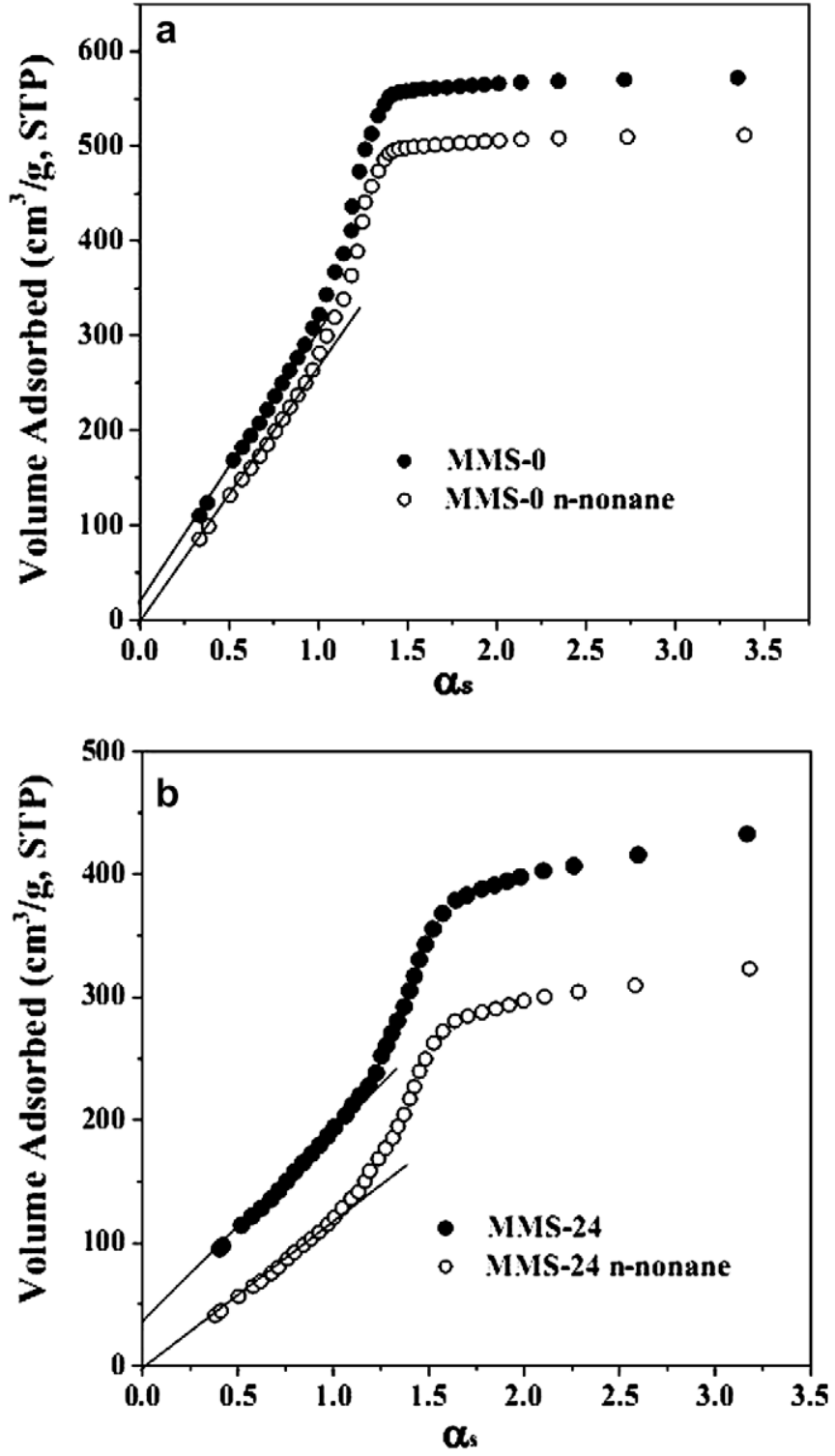

Fig. 3. Comparative $\alpha_{\mathrm{s}}$ plots before and after pre-adsorption of n-nonane on MMS-0 (a) and MMS-24 (b).

confirming the complete filling or blocking of the micropores. In comparison with MMS-0 (Fig. 3a), the amount of nitrogen adsorbed decreases dramatically for MMS-24 (Fig. 3b) within the linear region of $\alpha_{\mathrm{s}}$ plot, suggesting the presence of more micropores for MMS-24. Table 1 summarizes the textural properties of MMS materials, where the micropore volume $\left(V_{\text {micro }}\right)$ is obtained by using the difference of nitrogen adsorption isotherms before and after n-nonane pre-adsorption. Particularly, the nitrogen adsorption results indicate the presence of micropores in all samples, while no silicalite- 1 structure is observed in high-angle XRD for the samples aged less than $18 \mathrm{~h}$. This disparity could be attributed to the different nature between the micropores in the sample aged for shorter time and those in silicalite-1. The former were formed by the penetration of the hydrophilic poly (ethylene oxide) chain from the triblock copolymer template into the silica framework during the sol-gel synthesis [40], and they existed in the amorphous silica wall. Thus, the original micropores have no peaks in high-angle XRD due to their amorphous structures, while the zeolite-like structure incorporated in the walls could exhibit obvious high-angle XRD peaks due to their crystalline nature. Despite the slight decrease of specific surface area, the values of the micropore 
Table 1

Physical properties of MMS materials obtained from the nitrogen adsorption isotherm at $77 \mathrm{~K}$.

\begin{tabular}{lllll}
\hline Sample & $\begin{array}{l}S_{\text {BET }} \\
\left(\mathrm{m}^{2} \mathrm{~g}^{-1}\right)\end{array}$ & $\begin{array}{l}V_{\mathrm{t}} \\
\left(\mathrm{cm}^{3} \mathrm{~g}^{-1}\right)\end{array}$ & $\begin{array}{l}V_{\text {micro }} \\
\left(\mathrm{cm}^{3} \mathrm{~g}^{-1}\right)^{\mathrm{a}}\end{array}$ & $\begin{array}{l}\text { Micropore area } \\
\left(\mathrm{m}^{2} \mathrm{~g}^{-1}\right)^{\mathrm{a}}\end{array}$ \\
\hline MMS-0 & 797 & 0.85 & 0.08 & 104 \\
MMS-6 & 669 & 0.83 & 0.09 & 112 \\
MMS-12 & 653 & 0.80 & 0.10 & 128 \\
MMS-18 & 599 & 0.70 & 0.12 & 157 \\
MMS-24 & 536 & 0.66 & 0.17 & 222 \\
Silicalite-1 & 367 & 0.21 & 0.18 & 237 \\
\hline
\end{tabular}

a Obtained using the volume blocked by n-nonane.

volume for all the samples increase with increasing aging time. Table 1 indicates that all the micro/mesoscopic composites possess high BET area and large total pore volume. In particular, the obtained MMS-24, with long aging time ( $24 \mathrm{~h}$ ) of seeds, still has high specific area of $536 \mathrm{~m}^{2} \mathrm{~g}^{-1}$ and large total pore volume of $0.66 \mathrm{~cm}^{3} \mathrm{~g}^{-1}$. As compared with other similar micro/mesoscopic materials reported in previous literatures [22,29], the BET areas of the present biporous silicas seem lower, whereas, the micropore volume is higher, owing to the well crystallized zeolites incorporated in the mesoporous framework.

TEM images in Fig. 4 show that most of the obtained samples exhibit spherical morphology, although some of them have a few defects. Furthermore, the particle size of the synthesized material is small with diameter in range from 50 to $200 \mathrm{~nm}$. It is supposed that the co-surfactant $\mathrm{CTAB}$ and the co-solvent ethanol play an important role in the formation of the spherical morphology. The addition of ethanol to the solution reduces the reaction rate, which is attributable to the formation of curved morphologies by decreasing the local surface curvature energy [41]. On the other hand, the presence of CTAB promoted the interaction between the mixed micelles and the silicate species, leading to the formation of spherical particles [42]. Fig. 4b further exhibits that the obtained silica spheres present a worm-like mesoporous structure which is in accordance with the nitrogen adsorption and XRD analysis results. The TEM image of MMS-24 and the corresponding electron diffraction (ED) pattern (inset) in Fig. 4c demonstrate multi-crystals, suggesting the sample is not physical mixture of bulk zeolite and mesoporous solid. Assembled from zeolite seeds aged for $24 \mathrm{~h}$, MMS-24 preserves spherical morphology in which zeolites incorporated into silica framework are in the form of nanocrystals with long-range atomic order.

\subsection{Static adsorption behavior}

MMS-0 and MMS-24, the samples with no and well-crystalized zeolites in the mesoporous framework, respectively, were adopted here to estimate their hydrophobicities and adsorption properties for VOCs, comparing with microporous silicalite- 1 zeolite. Fig. 5 shows the adsorption isotherms of benzene on MMS-0, MMS-24 and silicalite- 1 at temperature of 25,35 and $45^{\circ} \mathrm{C}$, respectively. The amount of benzene adsorbed at low pressure increases in the order of silicalite-1 $>$ MMS-24 $>$ MMS-0 (Fig. 5a-c), with the increasing microporosities of the materials. The adsorption in micropores at low pressure is a direct consequence of the overlap of the adsorption field from the adjacent walls of micropores. Comparing with silicalite-1 (Fig. 5c), the adsorption isotherms for both MMS-0 (Fig. 5a) and MMS-24 (Fig. 5b) exhibit capillary condensation steps which attribute to the presence of the mesopores in these materials. Hence the adsorption isotherms for benzene on MMS-0 and MMS-24 exhibit a combination of microporous and mesoporous adsorptive behavior. In particular, the uptake on MMS-24 at high pressure after capillary condensation associates with the presence of large amount of textural mesoporosity, which is attributed to interparticle voids [43]. The equilibrium adsorption capacity of benzene on MMS-24 $\left(6.61 \mathrm{mmol} \mathrm{g}^{-1}\right)$ is approximately three times higher than that on silicalite- $1\left(1.60 \mathrm{mmol} \mathrm{g}^{-1}\right)$ at relatively high temperature $45^{\circ} \mathrm{C}$ (Table $\mathrm{S} 1$ ). This result can be explained by the fact that static VOCs adsorption capacity is proportional to the total pore volume, which is consistent with the literature [1].

The hydrophilic/hydrophobic properties of MMS-0, MMS-24 and silicalite- 1 were estimated by water adsorption isotherms at temperature of 25,35 and $45{ }^{\circ} \mathrm{C}$, respectively (Fig. 6). In Fig. 6a, the isotherms for water adsorption on MMS-0 at all the tested temperatures are of type $\mathrm{V}$, indicating the weak interaction between adsorbent and adsorbate [44]. These results are very similar to the behavior of water adsorption isotherm on SBA-15 [45]. The appearance of capillary condensation at high pressure confirms that MMS-0 is somewhat hydrophilic in nature due to a certain amount of hydrophilic silanol groups on its surface. In the case of MMS-24 (Fig. 6b), the water adsorption isotherms are of type II in accordance with IUPAC classification, indicating that the interaction between adsorbent and adsorbate is weaker than that of adsorbate and adsorbate, and the silica surface possesses a high degree of hydrophobicity. It is interesting to note that there is no capillary condensation for the isotherms of MMS-24. The difference in capillary condensation behavior between MMS-0 and MMS-24 is possibly attributable to their different hydrophobic/hydrophilic properties [44]. In comparison with isotherms on MMS-24 (Fig. 6b), the amount of water adsorbed on silicalite-1 (Fig. 6c) is relatively high at low pressure, which can be explained by the differences in pore diameters. In the micropores, the superposition of fields from the close separated opposing pore walls as a result of dispersion interactions enhances the physical adsorption behavior. On the other hand, with the increase in pore size, an increased
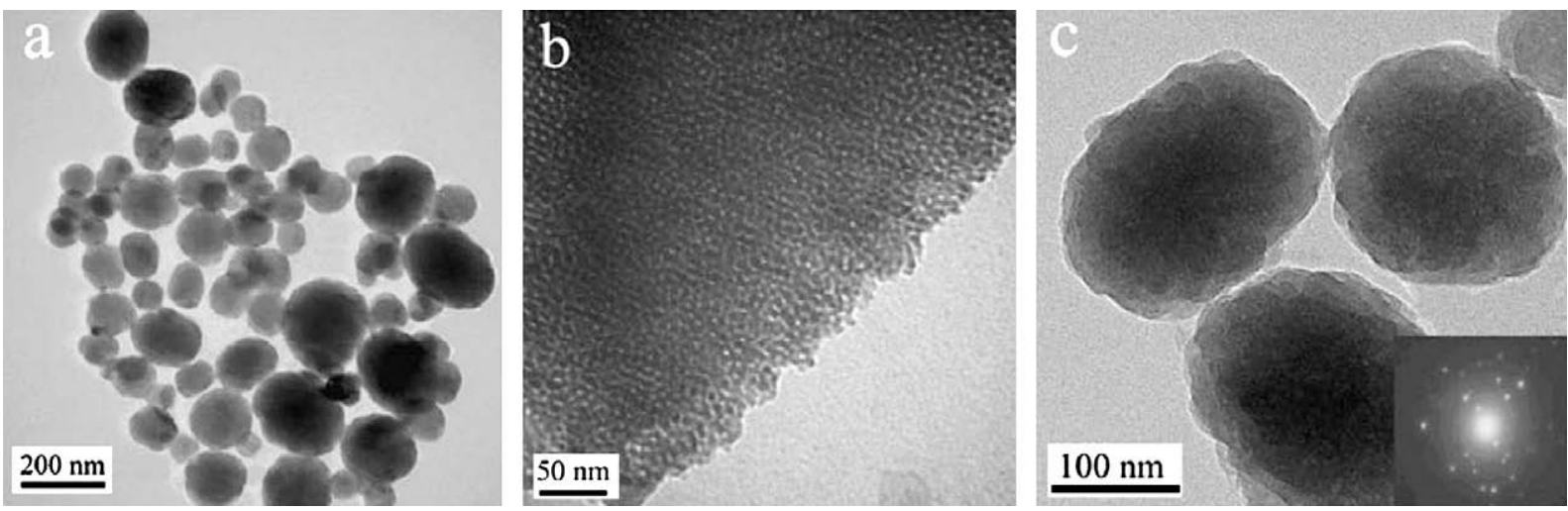

Fig. 4. TEM images of micro/mesoscopic silicas prepared with different aging time: $0 \mathrm{~h}(\mathrm{a}, \mathrm{b})$ and $24 \mathrm{~h}$ (c). Inset (c) is the corresponding ED pattern. 

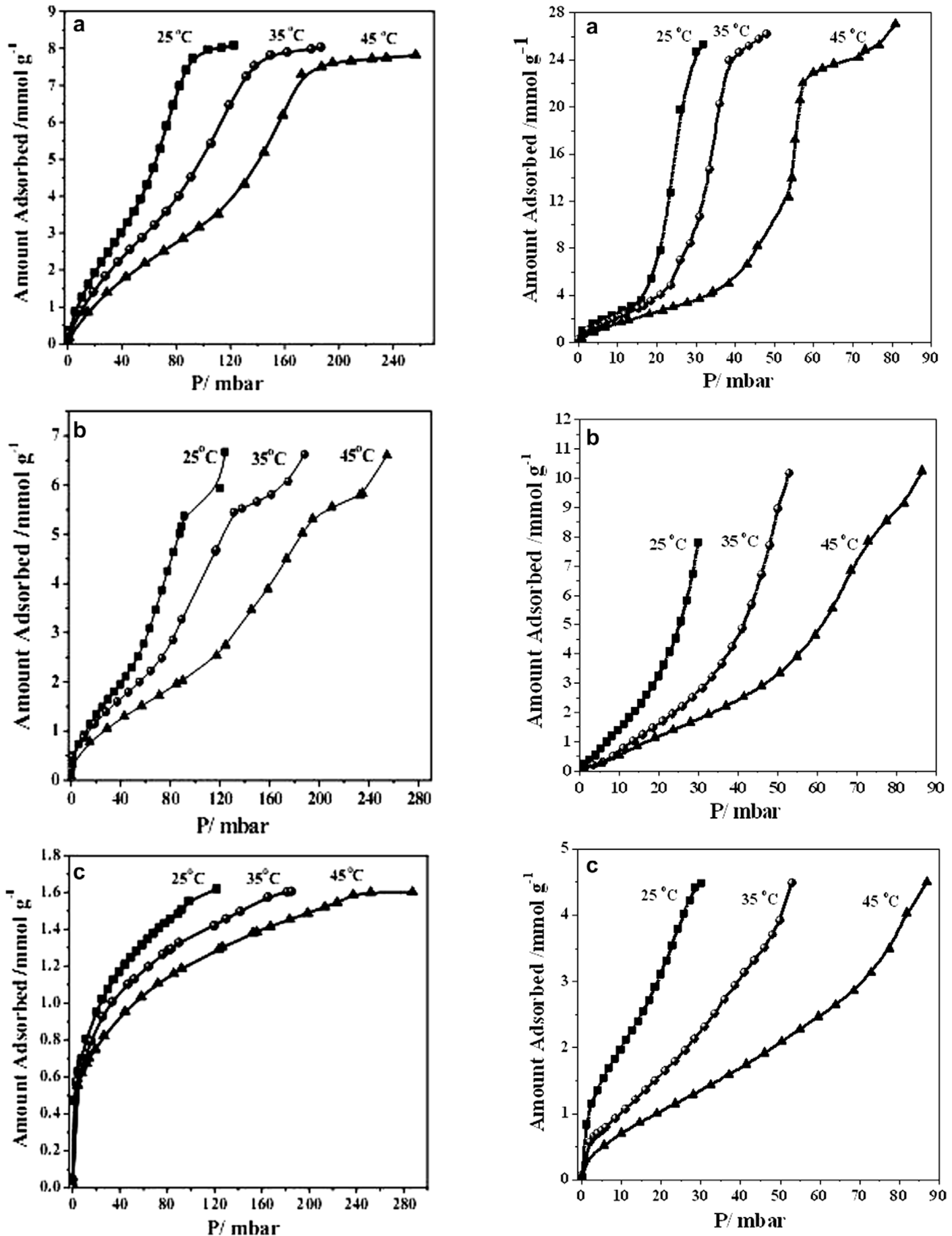

Fig. 5. Adsorption isotherms of benzene on MMS-0 (a), MMS-24 (b) and silicalite-1 (c) at various temperatures.

Fig. 6. Adsorption isotherms of water on MMS-0 (a), MMS-24 (b) and silicalite-1 (c) materials at various temperatures. 
distance between silanol groups on the curved pore surfaces would improve the hydrophobicity [46]. The strong curvature of the small pore size favors hydrogen bonding of the surface hydroxyls. On the contrary, the silanols are too far apart in the wide pores. At temperature of $45^{\circ} \mathrm{C}$, the equilibrium adsorption capacity for water on MMS-0, MMS-24 and silicalite-1 are 27.07, 10.24 and 4.5 mmol g ${ }^{-1}$, respectively (Table S1). Therefore, it can be concluded that the obtained micro/mesoporous MMS-24 material possesses excellent hydrophobicity and lipophilicity.

The Henry's constants calculated from the adsorption data at low pressure $(P<3$ mbar) are displayed in Fig. S1, which reflect adsorption affinity in the line region of the adsorption isotherm. As expected, the Henry's constants of all the obtained samples decrease with the increase in temperature. In Fig. S1a, the Henry's constants for the adsorption of water are systematically higher than those of benzene on MMS-0 material. However, these values on micro/mesoporous composites MMS-24 exhibit an opposite trend (Fig. S1b). Compared with MMS-0, MMS-24 possesses less surface silanols due to the perfect zeolite framework in the walls with less $\mathrm{Si}-\mathrm{OH}$ defects. For pure silicalite- 1 zeolite (Fig. S1c), the Henry's constants are obviously higher than those of MMS-0 and MMS-24 due to the strong adsorption energy in micropores.

The heat of adsorption represents the strength of the interactions between the adsorbent and the adsorbate, hence can be used to gauge the compatibility between them. The adsorption isosteric heat for the adsorption of benzene and water on different adsorbents, namely MMS-0, MMS-24 and silicalite-1, was derived from the Clausius-Clapeyron equation and are shown in Fig. 7. For all the samples, the isosteric heat of adsorption reaches a constant value after an initial sharp decrease. It is obvious that in the initial steps of the adsorption the strong interaction between the hydroxyl groups and the adsorbate (water molecules or $\pi$-electrons from the benzene rings) results in high adsorption heat, in accordance with literature information [37]. It is this interaction plays a dominate role at the early stage of the adsorption. This phenomenon is supported by the previously obtained Henry's constants. The decrease of the adsorption heat may be attributed to heterogeneity of adsorption sites [5]. Afterwards, owing to the confinement effect, the adsorption heat decreases gradually with the increase in adsorbate loading and then get close to the heat of liquefaction in bulk liquid phase. In comparison with MMS-0 (Fig. 7a), the low adsorption heat for MMS-24 (Fig. 7b) at initial stage indicates the hydrophobic character of its surface, viz. less interaction between silanols and water molecules. In the case of the silicalite-1 sample (Fig. 7c), the adsorption heat is generally higher than that of the other two samples. Without relative open mesopores, the dense micropores in silicalite- 1 enhance the adsorbent-adsorbate interactions caused by van der Waals forces.

\subsection{Dynamic adsorption behavior}

The investigation of adsorption breakthrough was conducted for the removal of typical VOCs, such as benzene, by MMS-0, MMS-24 and silicalite-1 materials. The investigation was undertaken at low adsorbate concentration under dry and wet conditions respectively with aim to identify the performance of dynamic VOCs removal (Fig. 8). In the case of dry condition, the breakthrough time is about 27 min for both MMS-0 and MMS-24, while for silicalite- 1 the time is $22 \mathrm{~min}$. Generally, the longer the breakthrough time is, the higher the dynamic adsorption capacity becomes. In addition, the breakthrough curve for MMS-24 increases more rapidly than that for MMS-0. With respect to the experiments performed in humid environment $(38 \% \mathrm{RH})$, the breakthrough time is in the order of MMS-24 > silicalite- $1>$ MMS-0.
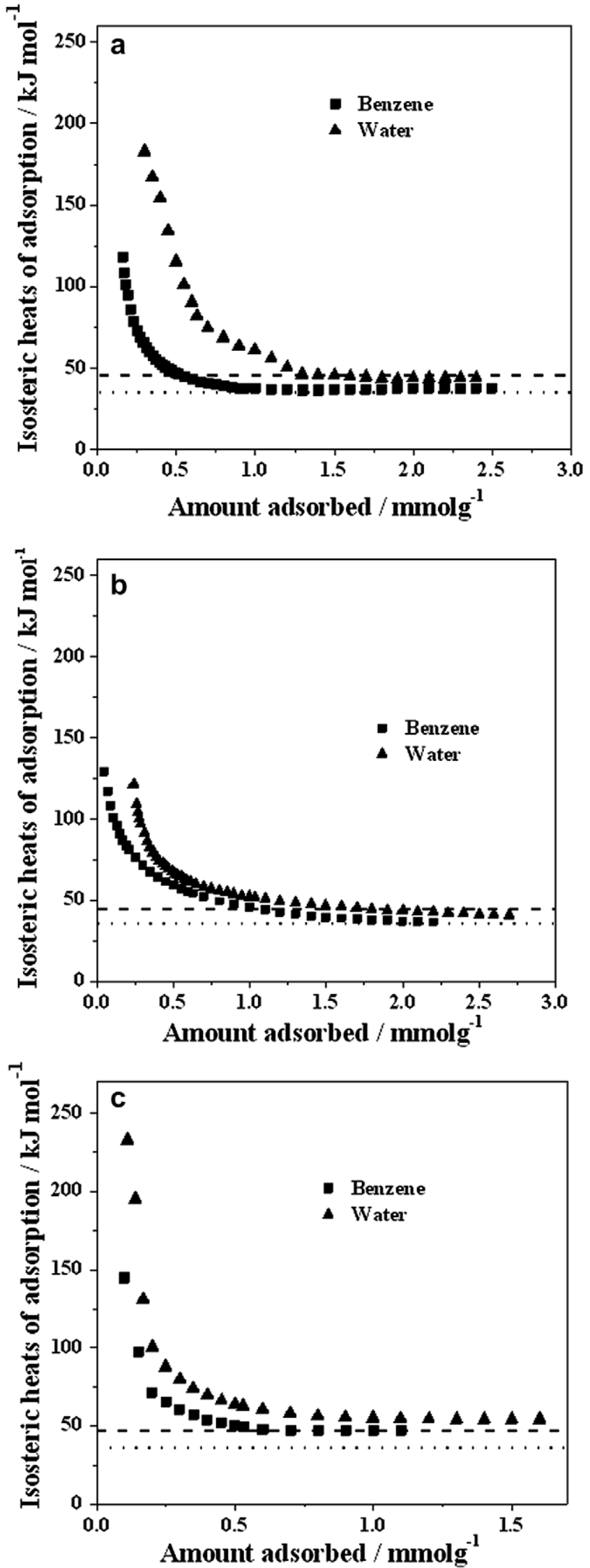

Fig. 7. Variation of the isosteric heat for the adsorption of benzene and water on MMS-0 (a), MMS-24 (b) and silicalite-1 (c). The dot line and the dash line represent the standard enthalpies of vaporization of benzene and water, respectively. 


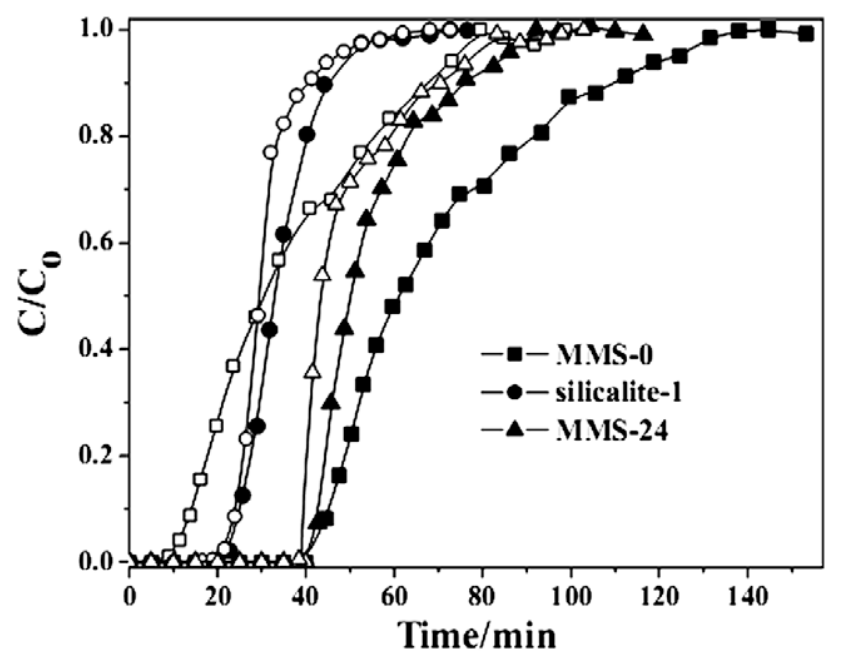

Fig. 8. The breakthrough curves of benzene on MMS-0, silicalite- 1 and MMS-24. The filled symbols are under dry conditions and the open symbols are under wet conditions (38\% RH).

Table 2

Dynamic adsorption capacity of benzene on MMS-0, MMS-24 and silicalite-1 under dry and wet conditions.

\begin{tabular}{llll}
\hline Samples & \multicolumn{3}{l}{ Dynamic adsorption capacity $Q\left(\mathrm{mmol} / \mathrm{g}_{\text {adsorbent }}\right)$} \\
\cline { 2 - 4 } & $Q_{\text {dry }}$ & $Q_{38 \% \mathrm{RH}}$ & $Q_{38 \% \mathrm{RH}} / Q_{\mathrm{dry}}(\%)$ \\
\hline MMS-0 & 0.63 & 0.13 & 21 \\
MMS-24 & 0.62 & 0.52 & 85 \\
Silicalite-1 & 0.41 & 0.37 & 91 \\
\hline
\end{tabular}

The amount of benzene adsorbed was obtained by measuring the area between the maximum baseline and the experimental curve [1]. Table 2 summarizes the dynamic adsorption capacities of benzene under dry $\left(Q_{d r y}\right)$ and humid environments $\left(Q_{38 \%} \mathrm{RH}\right)$, as well as the adsorption efficiency $\left(Q_{\mathrm{dry}} / Q_{38 \% \mathrm{RH}}\right)$ in the presence of water. MMS-0 exhibits the highest adsorption capacity $\left(0.630 \mathrm{mmol} / \mathrm{g}_{\text {adsorbent }}\right)$ in the absence of water. Whereas, under humid environment, the dynamic adsorption capacity of benzene is in the order of MMS- $24>$ silicalite- $1>$ MMS- 0 . The MMS-24 sample shows high efficiency towards benzene as $85 \%$ of its original capacity under dry condition, which is significantly higher than that of MMS-0 (20\%). In the presence of water, the polar water molecules would be adsorbed on the surface irreversibly, due to the formation of strong hydrogen bond between isolated pairs of silanol groups and adsorbed water. With respect to benzene adsorption, there are relatively weak interactions between the silica surface and the $\pi$-electrons of benzene molecules [9]. Hence polar silanol groups interact preferentially with water molecules compared with benzene molecules. For MMS-24, well crystallized zeolites incorporated in the mesoporous framework significantly decrease $\mathrm{Si}-\mathrm{OH}$ defects, resulting in the enhancement of the hydrophobicity of the surface. The dynamic competitive adsorption behavior shows a good agreement with the static adsorption experiments.

\section{Conclusions}

In this study, a series of hierarchical micro/mesoscopic silicas (MMS) with high surface area and large total pore volume were assembled from silicalite- 1 zeolite seeds in acid media, by using Pluronic P123 as a structure-directing agent. XRD and nitrogen adsorption/desorption analyses suggest that, after aging for $18 \mathrm{~h}$, the resultant bimodal composites (MMS-18 and MMS-24) exhibit good characters of both zeolite-like microporous and mesoporous structures. The TEM images further identify that the well crystallized zeolites are successfully incorporated into the framework of the mesoporous silicas rather than a physical mixture of bulk zeolite and mesoporous solid. Even with zeolite seeds aged for $24 \mathrm{~h}$, MMS-24 still possesses high surface area of $536 \mathrm{~m}^{2} \mathrm{~g}^{-1}$ and large total pore volume of $0.66 \mathrm{~cm}^{3} \mathrm{~g}^{-1}$. The microporosity of the MMS materials, which was evaluated by n-nonane pre-adsorption method, increases with the increase of aging time of zeolite seeds. The adsorption isotherms of benzene and water on MMS-24 indicate that the obtained bimodal composites have excellent hydrophobicity and good affinity towards aromatic benzene molecules. The equilibrium adsorption capacity for benzene on MMS-24 $\left(6.61 \mathrm{mmol} \mathrm{g}^{-1}\right)$ is approximately 3 times higher than that of silicalite-1 $\left(1.60 \mathrm{mmol} \mathrm{g}^{-1}\right)$. In the dynamic competitive adsorption measurement, MMS-24 shows a super hydrophobicity with $85 \%$ efficiency towards benzene in the presence of water. Thus, these bimodal micro/mesoporous materials as potential adsorbents would have a promising future in the field of VOCs removal.

\section{Acknowledgments}

This study was financially supported by National Natural Science Foundation of China(20725723 and 20807050), National Basic Research Program of China (2010CB732300) and the National High Technology Research and Development Program of China (2006AA06A310).

\section{Appendix A. Supplementary data}

Supplementary data associated with this article can be found, in the online version, at doi:10.1016/j.micromeso.2010.04.023.

\section{References}

[1] K. Kosuge, S. Kubo, N. Kikukawa, M. Takemori, Langmuir 23 (2007) 3095-3102.

[2] S. Brosillon, M.H. Manero, J.N. Foussard, Environ. Sci. Technol. 35 (2001) 35713575 .

[3] X.S. Zhao, O. Ma, G.O. Lu, Energ. Fuel. 12 (1998) 1051-1054.

[4] W. Makowski, P. Kustrowski, Micropor. Mesopor. Mater. 102 (2007) 283-289.

[5] H. Vinh-Thang, Q. Huang, M. Eic, D. Trong-On, S. Kaliaguine, Langmuir 21 (2005) 5094-5101

[6] Y.C. Long, H.W. Jiang, H. Zeng, Langmuir 13 (1997) 4094-4101.

[7] C.H. Christensen, K. Johannsen, I. Schmidt, J. Am. Chem. Soc. 125 (2003) 1337013371.

[8] A. Matsumoto, H. Misran, K. Tsutsumi, Langmuir 20 (2004) 7139-7145.

[9] R. Serna-Guerrero, A. Sayari, Environ. Sci. Technol. 41 (2007) 4761-4766.

[10] J.C. Groen, W.D. Zhu, S. Brouwer, S.J. Huynink, F. Kapteijn, J.A. Moulijn, J. PérezRamírez, J. Am. Chem. Soc. 129 (2007) 355-360.

[11] J.C. Groen, T. Bach, U. Ziese, J. Am. Chem. Soc. 127 (2005) 10792-10793.

[12] J.C. Groen, J.A. Moulijn, J. Pérez-Ramírez, Ind. Eng. Chem. Res. 46 (2007) 41934201.

[13] D. Trong On, S. Kaliaguine, Angew. Chem. Int. Ed. 40 (2001) 3248-3251.

[14] M.B. Yue, L.B. Sun, T.T. Zhuang, X. Dong, Y. Chun, J.H. Zhu, J. Mater. Chem. 18 (2008) 2044-2050.

[15] A.A. Campos, L. Martins, L.L. de Oliveira, C.R. da Silva, M. Wallau, E.A. UrquietaGonzález, Catal. Today 107-108 (2005) 759-767.

[16] S.I. Cho, S.D. Choi, J.H. Kim, G.J. Kim, Adv. Funct. Mater. 14 (2004) 49-54.

[17] Y.M. Fang, H.Q. Hu, J. Am. Chem. Soc. 128 (2006) 10636-10637.

[18] T.O. Do, S. Kaliaguine, J. Am. Chem. Soc. 125 (2003) 618-619.

[19] T.O. Do, A. Nossov, M.A. Springuel-Huet, C. Schneider, J.L. Bretherton, C.A. Fyfe, S. Kaliaguine, J. Am. Chem. Soc. 126 (2004) 14324-14325.

[20] Y. Liu, T.J. Pinnavaia, Chem. Mater. 14 (2002) 3-5.

[21] Y. Liu, W. Zhang, T.J. Pinnavaia, J. Am. Chem. Soc. 122 (2000) 8791-8792.

[22] C.S. Carr, S. Kaskel, D.F. Shantz, Chem. Mater. 16 (2004) 3139-3146.

[23] M.L. Gonçalves, L.D. Dimitrov, M.H. Jordão, M. Wallau, E.A. Urquieta-González, Catal. Today 133 (2008) 69-79.

[24] L. Frunz, R. Prins, G.D. Pirngruber, Micropor. Mesopor. Mater. 88 (2006) 152 162.

[25] D. Li, D. Su, J. Song, X. Guan, K. Hofmann, F.S. Xiao, J. Mater. Chem. 15 (2005) 5063-5069.

[26] Y. Liu, W. Zhang, T.J. Pinnavaia, Angew. Chem. Int. Ed. 40 (2001) 1255-1258.

[27] Y. Xia, R. Mokaya, J. Mater. Chem. 14 (2004) 3427-3435. 
[28] S.Q. Zeng, J. Blanchard, M. Breysse, Y.H. Shi, X.T. Su, H. Nie, D.D. Li, Appl. Catal. A - Gen. 298 (2006) 88-93.

[29] Y. Han, S. Wu, Y. Sun, D. Li, F.S. Xiao, J. Liu, X. Zhang, Chem. Mater. 14 (2002) 1144-1148.

[30] Q. Hu, J.J. Li, Z.P. Hao, L.D. Li, S.Z. Qiao, Chem. Eng. J. 149 (2009) 281-288.

[31] Q. Hu, B.J. Dou, H. Tian, J.J. Li, P. Li, Z.P. Hao, Micropor. Mesopor. Mater. 129 (2009) 30-36.

[32] B.J. Schoeman, O. Regev, Zeolites 17 (1996) 447-456.

[33] A. Katiyar, S. Yadav, P.G. Smirniotis, N.G. Pinto, J. Chromatogr. A 1122 (2006) $13-20$.

[34] A. Silvestre-Albero, E.O. Jardim, E. Bruijn, V. Meynen, P. Cool, A. SepúlvedaEscribano, J. Silvestre-Albero, F. Rodríguez-Reinoso, Langmuir 25 (2009) 939943.

[35] T.R. Pauly, V. Petkov, Y. Liu, S.J.L. Billinge, S.J.L. Billinge, T.J. Pinnavaia, J. Am. Chem. Soc. 124 (2002) 97-103.

[36] K.S.W. Sing, D.H. Everett, R.A.W. Haul, L. Moscou, R.A. Pierotti, J. Rouquérol, T. Siemieniewska, Pure Appl. Chem. 57 (1985) 603-619.
[37] Q. Huang, H. Vinh-Thang, A. Malekian, M. Eić, D. Trong-On, S. Kaliaguine, Micropor. Mesopor. Mater. 87 (2006) 224-234.

[38] S.J. Gregg, J.F. Langford, Trans. Faraday Soc. 65 (1969) 1394-1400.

[39] M. Jaroniec, M. Kruk, J.P. Olivier, Langmuir 15 (1999) 5410-5413.

[40] M. Kruk, M. Jaroniec, C.H. Ko, R. Ryoo, Chem. Mater. 12 (2000) 1961-1968.

[41] M. Mesa, L. Sierra, B. López, A. Ramirez, J.L. Guth, Solid State Sci. 5 (2003) 1303-1308.

[42] J.P. Hanrahan, A. Donovan, M.A. Morris, J.D. Holmes, J. Mater. Chem. 17 (2007) 3881-3887.

[43] Y. Liu, T.J. Pinnavaia, J. Mater. Chem. 14 (2004) 1099-1103.

[44] Y. Zhai, B. Tu, D. Zhao, J. Mater. Chem. 19 (2009) 131-140.

[45] E. Van Bavel, V. Meynen, P. Cool, K. Lebeau, E.F. Vansant, Langmuir 21 (2005) 2447-2453.

[46] S. Eslava, M.R. Baklanov, J. Urrutia, C.E.A. Kirschhock, K. Maex, J.A. Martens, Adv. Funct. Mater. 18 (2008) 3332-3339. 